\title{
ПЕРЕЖИВАНИЕ БОЛИ ПРИ РАЗЛИЧНЫХ АКЦЕНТУАЦИЯХ СВОЙСТВ ТЕМПЕРАМЕНТА
}

\author{
(С Северьянова Л.А. ${ }^{1}$, Плотников Д.В. ${ }^{2}$, Крюков А.А. ${ }^{l}$, Долгинцев М.Е. \\ ${ }^{1}$ Кафедра патофизиологии, ${ }^{2}$ кафедра психиатрии \\ Курского государственного медицинского университета, Курск \\ E-mail: kriukov-aa@yandex.ru
}

\begin{abstract}
Цель нашей работы - раскрыть индивидуальные особенности переживания боли у людей с различными типами темперамента, который служит интегративной биопсихосоциальной детерминантой индивидуальности. 287 здоровых волонтеров исследованы специальным тестом, основанным на изменениях трех биполярных факторов темперамента: эмоциональности, социальной и предметной активностей. Отобраны 178 исследуемых, у которых значения факторов близки к их полюсам (акцентуации). У них затем исследована боль, вызванная погружением кисти руки в холодную $\left(+4{ }^{\circ} \mathrm{C}\right)$ воду на 1 мин, и измеряли пороги возникновения и выраженности (по шкалам) сенсорных и эмоциональных реакций, а также цветовой выбор. Установлено, что болевая чувствительность и связанные с болью реакции более выражены при акцентуированных свойствах темперамента, особенно астенических (эмоциональной нестабильности, социальной и предметной пассивности), и в большей степени у женщин. Сделано заключение, что определение типа темперамента позволяет прогнозировать особенности переживания боли и индивидуализировать меры ее профилактики и лечения.
\end{abstract}

Ключевые слова: холодовая боль, темперамент, боль-ассоциированные реакции.

\section{PAIN EXPERIENCE AND ACCENTUATED TRAITS OF TEMPERAMENT Severyanova L.A. ${ }^{1}$, Plotnikov D..$^{2}$, Kryukov A.A. ${ }^{1}$, Dolgintsev M.E. ${ }^{l}$}

${ }^{1}$ Pathophysiology Department, ${ }^{2}$ Psychiatry Department of Kursk State Medical University, Kursk

The aim of our study is to reveal the individual peculiarities of pain experience in humans with different temperament types which serve as an integrative biopsychosocial determinant of an individuality. 287 pain-free volunteers were investigated with the special test based on measuring three generalized bipolar temperament factors: emotionality, social and object activities. 178 participants were chosen who had the factors outcome measures near to the poles (accentuation). All these participants carried out the cold pressor test after which the pain experience and related reactions according to self-report scales and the preferable colour among 8 colours set were assessed. It was found that in the participants with the accentuated temperament traits the intensity of pain, sensory perception, emotional experience, and catastrophic thinking were higher than in absence of accentuations. The trend to the greater expression of pain outcome measures was found in persons with the accentuated asthenic temperament traits (emotional instability, social and object passivity) especially in females. Our findings show that the determination of temperament traits allows to predict the level of pain experience and pain - related reactions and gives the opportunity to individualize pain management and prophylaxis beforehand.

Keywords: cold-evoked pain, temperament, pain-related reactions.

По современным представлениям, боль сложное психофизиологическое состояние человека, включающее, кроме специфического ощущения, эмоциональный, вегетативный и поведенческий компоненты. Установлено, что ее формирование - результат сложного взаимодействия биологических, физиологических и социальных механизмов. Определены специализированные сенсорные нейроны, сигнализирующие о повреждении ткани, а также сложная матрица, включающая многие структуры в ЦНС [3, 4, 6, 19, 22]. Продолжено изучение роли нейротрансмиттерных систем в формировании боли: серотониновой, опиоидной, катехоламиновой, ГАМК-эргической $[5,8,16]$. Достигнут значительный прогресс в изучении индивидуальных особенностей в переживании боли, в частности исследован вклад генетических механизмов в индивидуальную вариабельность боли и доказан их полиморфизм [11, 15]. Вы- делены психофизиологические процессы, связанные с болью и влияющие на нее: тревожность, катастрофирование, депрессия [13, 23].

Однако остаются не выясненными механизмы, определяющие фенотип болевой чувствительности и, следовательно, интенсивность и характер болевого процесса и связанных с ним эмоциональных, вегетативных и поведенческих компонентов. Особая актуальность исследования этой проблемы обусловлена необходимостью прогнозировать индивидуальные реакции на болевое раздражение для эффективной профилактики и лечения.

Мы полагаем, что для решения этой проблемы необходимо использовать интегральный показатель индивидуальности, отражающий обобщенно биологический уровень и базовые свойства психики. Таким показателем может служить темперамент. 
Цель нашей работы - установить индивидуальные особенности холодовой боли у лиц с различными типами темперамента.

\section{МАТЕРИАЛЫ И МЕТОДЫ ИССЛЕДОВАНИЯ}

Свойства темперамента исследованы у 287 студентов - волонтеров медицинского университета в возрасте $20,1 \pm 0,1$ года, из которых для дальнейшего изучения были отобраны 178 человек (44 мужчин и 134 женщины), имевших усиление полярных свойств темперамента, и 16 - не имевших. Перед началом исследования все участники боли проинформированы об условиях его проведения и заполнили карты добровольного согласия на участие. В анамнезе участников отсутствовали заболевания и хронические болевые синдромы.

Исследование было утверждено Этическим комитетом Курского государственного медицинского университета и соответствует требованиям Хельсинкской декларации.

Определение типа темперамента было основано на представлении о нем как о совокупности формально-динамических свойств психики человека, в которых отражены базовые свойства нервной системы $[12,28]$.

Применен Тест акцентуации свойств темперамента ТАСТ [9]. Тест включает 125 вопросов и позволяет оценить в баллах следующие шкалы: 1) гипертимность (оптимизм, жизнерадостность), 2) социальная активность (потребность в социальных контактах), 3) энергичность (жажда деятельности), 4) нейротизм (переживание психического неблагополучия), 5) робость (застенчивость в социальных контактах), 6) агрессивность (вспыльчивость, раздражительность, вербальная конфликтность), 7) сенситивность (впечатлительность, ранимость, мягкосердечие), 8) эмоциональная лабильность (частая смена настроения, вегетосоматическая нестабильность), 9) ригидность (консерватизм, упрямство). 10-я шкала - контрольная, оценивающая правдивость: при значениях по этой шкале более 5 баллов результат признавали недостоверным.

C применением факторного анализа шкал TACT при разработке метода установлено, что структура темперамента обусловлена тремя биполярными факторами второго порядка, отражающими сочетание свойств (шкал) в типах. Эти факторы: 1-й - эмоциональная стабильность (ЭС) эмоциональная нестабильность (ЭН); 2-й фактор: социальная активность (СА) - социальная пассивность (СП); 3-й фактор: предметная активность (ПА) - предметная пассивность (ПП).
Выраженность противоположных полюсов биполярных факторов измеряли с помощью уравнений регрессии в безразмерных и сопоставимых единицах - стенах. Диапазон колебаний 4-7 стенов расценивали как нормативный. Доминирование одного из полюсов или дефицит выраженности противоположного полюса квалифицировали как акцентуацию соответствующего свойства. При значениях 8 и 3 стена констатировали умеренную акцентуацию соответствующего полюса фактора; при значениях 9 и 2 стена - выраженную акцентуацию, а 10 и 1 стен свидетельствовали о сильно выраженной акцентуации.

В зависимости от характера акцентуаций исследуемые были разделены на две группы: с акцентуацией стенических свойств (ЭС, СА, ПА) и акцентуацией астенических свойств (ЭН, СП, ПП) - соответственно 65 и 98 человек.

Акцентуированные полюса биполярных факторов имели четкую тенденцию к определенным сочетаниям, формирующим стенические или астенические обобщенные характеристики темперамента. Стеническая направленность стимулировала активность взаимодействия с реальностью. Астеническая направленность свойств, напротив, ограничивала активность взаимодействия с реальностью.

Для исследования боли использована видоизмененная модель с холодовым раздражением кожи рук. Кисть руки исследуемого помещали для адаптации в воду комнатной температуры на 5 мин. Затем ту же руку погружали до лучезапястного сустава в контейнер емкостью 30 л с водой при $\mathrm{t} 4^{\circ} \mathrm{C}$ на 1 мин. Регистрировали (в сек.) момент появления болевого ощущения - порог болевой чувствительности, а затем через каждые 20 сек. оценивали характер переживаемой боли с помощью Многомерного вербально-цветового болевого теста [2]. Температуру воды поддерживали на постоянном уровне.

В соответствии с особенностями изучаемой модели мы сочли адекватными для ее оценки следующие шкалы теста.

1. Порог боли - момент ее появления в сек., когда чувство холода переходит в боль.

2. Интенсивность боли - по вербально-цветовой шкале, позволяющей выполнить два измерения. А) Оценку интенсивности боли производили по рейтинговой шкале в баллах: боль очень слабая (1 балл); слабая (2 балла); средней силы (3); сильная (4); очень сильная (5); невыносимая (6). Исследуемый отмечает градацию, соответствующую его собственному болевому ощущению. Б) Выбор цвета предпочтения представляет ассоциацию цвета с интенсивностью боли. Использовали цветовую шкалу, аналогичную 8-цветному тесту Люшера: синий (1), зеленый (2), 
красный (3), желтый (4), фиолетовый (5), коричневый (6), черный (7), серый (8).

3. Сенсорное восприятие боли. Шкала содержит 47 дескрипторов (определений), описывающих болевые ощущения. Исследуемому предлагали выбрать одно или несколько определений, наиболее близко описывающих его (ее) болевые ощущения (сенсорное восприятие). Количественно оценивали в баллах.

4. Эмоциональное отношение к боли. Шкала позволяет проводить качественную и количественную оценку в баллах субъективного отношения к боли. Содержит 25 дескриптов, отражающих внутреннее эмоционально-аффективное восприятие боли. Исследуемый выбирал определение, наиболее сходное с его переживанием боли.

Кроме перечисленных критериев, входящих в тест, определяли также выносливость к боли и когнитивные стратегии.

Выносливость к боли: исследуемый мог вынуть руку из воды, если возникала боль, которую он не мог больше выносить (отмечено время).

Одной из общепринятых когнитивных стратегий при оценке переживаний в период болевого раздражения является катастрофирование, которое трактуется как крайне негативное размышление и интерпретация происходящего события. Для оценки этого критерия через 3 мин. по окончании холодового раздражения исследуемому предлагали ответить «да» или «нет» на следующие вопросы.

1. Я не перестаю думать, как много боли это причиняет. 2. Я чувствую, что больше не смогу это выносить. 3. Сильно хочу, чтобы боль прекратилась. 4. Боюсь, что боль может стать сильнее. 5. Интересно знать, может ли случиться что-то серьезное. 6. Думаю, что никогда не станет лучше.

Исследуемому предлагали также произвольно описать свои мысли и переживания в период холодового воздействия.

Статистическую обработку производили с определением критерия Стьюдента и корреляционной связи (коэффициент Пирсона) между показателями болевой чувствительности, сенсорных и эмоциональных компонентов боли при разных типах темперамента, а также с оценкой достоверности разности долей. Использован пакет программ Microsoft Excel 2010.

\section{РЕЗУЛЬТАТЫ ИССЛЕДОВАНИЯ И ИХ ОБСУЖДЕНИЯ}

По данным применения ТАСТ сформированы три группы исследуемых.

- Имеющие акцентуацию стенических свойств темперамента (65 человек) - это: ЭС (эмоциональная зрелость, рационалистичность, уравновешенность, соматовегетативная стабильность); СА (интенсивность субъект-субъективных взаимодействий, оптимистичность, пластичность); ПА (склонность к интенсивному энергетическому взаимодействию с предметным миром).

- Имеющие акцентуацию астенических свойств темперамента (98 человек - это: ЭН (впечатлительность, ранимость, робость, тревожность, вспыльчивость, неустойчивость настроения, психовегетативная нестабильность); СП (низкая активность в социальных формах взаимодействия, пессимистичность, психомоторная замедленность, психическая ригидность); ПП (несклонность к интенсивной энергетической мобилизации в предметных сферах деятельности, пессимистичность, психовегетативная неустойчивость).

- $\mathrm{He}$ имеющие акцентуаций свойств темперамента (15 человек).

У всех участников выполнено исследование боли при холодовом раздражении. Полученные при этом у мужчин и женщин показатели приведены в таблице 1. Как видно из представленных данных, величины порогов боли у мужчин с акцентуированными стеническими и астеническими свойствами темперамента оказались на 16,8 и $19,1 \%$ соответственно ниже, чем их величины у мужчин, не имевших акцентуаций. У женщин же отношения были противоположными: пороги болевой чувствительности у участниц с усиленными свойствами темперамента превышали на 8,7-10,2\% аналогичные контрольные величины. Следует при этом отметить, что у женщин без акцентуаций свойств темперамента болевая чувствительность при холодовом раздражении была статистически достоверно (при $р<0,05$ ) выше ее уровня у мужчин аналогичной группы без усиленных темпераментальных свойств.

Аналогичные соотношения установлены и для показателя интенсивности боли через 20 сек. от начала раздражения, а именно: у мужчин с акцентуацией стенических и астенических свойств темперамента он оказался выше на $58-67 \%$, а у женщин этих же групп - на 36,7$43,8 \%$ ниже, чем у лиц без акцентуаций.

С увеличением времени холодового раздражения у всех исследуемых наблюдали рост показателей интенсивности боли. Во всех группах, кроме группы женщин без акцентуаций темпераментальных свойств, увеличение интенсивности боли в конце исследования (через 60 сек. от начала) по отношению к первому измерению (через 20 сек.) было статистически достоверным: у мужчин с акцентуацией стенических свойств - больше на $212 \%$ $(\mathrm{p}<0,001)$, астенических - на 235\% ( $<<0,001)$, без акцентуаций $-270 \%(\mathrm{p}<0,05)$, а у женщин - на $74 \%, 100 \%(\mathrm{p}<0,001)$ и $13,9 \%$ соответственно. 
Таблица 1

Величины $(\mathrm{M} \pm \mathrm{m})$ показателей холодовой боли у исследуемых с различными свойствами темперамента

\begin{tabular}{|c|c|c|c|c|c|c|c|}
\hline \multirow{2}{*}{ Группы } & \multirow[b]{2}{*}{$\mathrm{n}$} & \multirow[b]{2}{*}{$\begin{array}{l}\text { Появление } \\
\text { боли (сек.) }\end{array}$} & \multicolumn{3}{|c|}{ Интенсивность (баллы) } & \multirow{2}{*}{$\begin{array}{c}\text { Сенсорное } \\
\text { восприятие } \\
\text { (баллы) }\end{array}$} & \multirow{2}{*}{$\begin{array}{c}\text { Эмоциона- } \\
\text { льное } \\
\text { переживание } \\
\text { (баллы) }\end{array}$} \\
\hline & & & $\begin{array}{c}20 \\
\text { Сек. }\end{array}$ & $\begin{array}{c}40 \\
\text { Сек. }\end{array}$ & $\begin{array}{c}60 \\
\text { Сек. }\end{array}$ & & \\
\hline \multicolumn{8}{|c|}{ мужчины } \\
\hline $\begin{array}{l}\text { Акцентуация } \\
\text { стенических } \\
\text { свойств }\end{array}$ & 19 & $21,3 \pm 2,3$ & $1,6 \pm 0,3$ & $3,1 \pm 0,3$ & $3,4 \pm 0,3$ & $4,3 \pm 0,1$ & $4,1 \pm 0,2$ \\
\hline $\begin{array}{l}\text { Акцентуация } \\
\text { астенических } \\
\text { свойств }\end{array}$ & 18 & $20,7 \pm 2,3$ & $1,7 \pm 04$ & $3,0 \pm 0,2$ & $4,0 \pm 0,3$ & $4,1 \pm 0,2$ & $3,6 \pm 0,3$ \\
\hline $\begin{array}{l}\text { Без акцентуации } \\
\text { свойств }\end{array}$ & 7 & $25,6 \pm 4,1^{*}$ & $1,0 \pm 0,5^{*}$ & $3,0 \pm 0,8$ & $3,7 \pm 0,9$ & $3,8 \pm 0,2$ & $3,5 \pm 0,4$ \\
\hline \multicolumn{8}{|c|}{ женщины } \\
\hline $\begin{array}{l}\text { Акцентуация } \\
\text { стенических } \\
\text { свойств }\end{array}$ & 46 & $16,1 \pm 1,6$ & $2,3 \pm 0,2$ & $3,6 \pm 0,2$ & $4,0 \pm 0,2$ & $4,7 \pm 0,01^{*}$ & $3,9 \pm 0,2$ \\
\hline $\begin{array}{l}\text { Акцентуация } \\
\text { астенических } \\
\text { свойств }\end{array}$ & 80 & $20,7 \pm 2,3$ & $2,1 \pm 02$ & $3,4 \pm 0,1$ & $4,2 \pm 0,1$ & $4,5 \pm 0,1$ & $4,1 \pm 0,1$ \\
\hline $\begin{array}{l}\text { Без акцентуации } \\
\text { свойств }\end{array}$ & 8 & $14,9 \pm 2,6^{*}$ & $3,6 \pm 1,5^{*}$ & $3,2 \pm 0,3$ & $4,1 \pm 0,4$ & $3,3 \pm 0,6^{*}$ & $3,4 \pm 0,6$ \\
\hline
\end{tabular}

Примечание: * - статистически достоверные различия (при р <0,05) между показателями в сопоставлениях: порог боли и ее интенсивность (через 20 сек.): между группами мужчин и женщин без акцентуации свойств темперамента; сенсорное восприятие: между двумя группами женщин: с акцентуацией стенических свойств темперамента и без акцентуаций; $\mathrm{n}$ - число исследуемых.

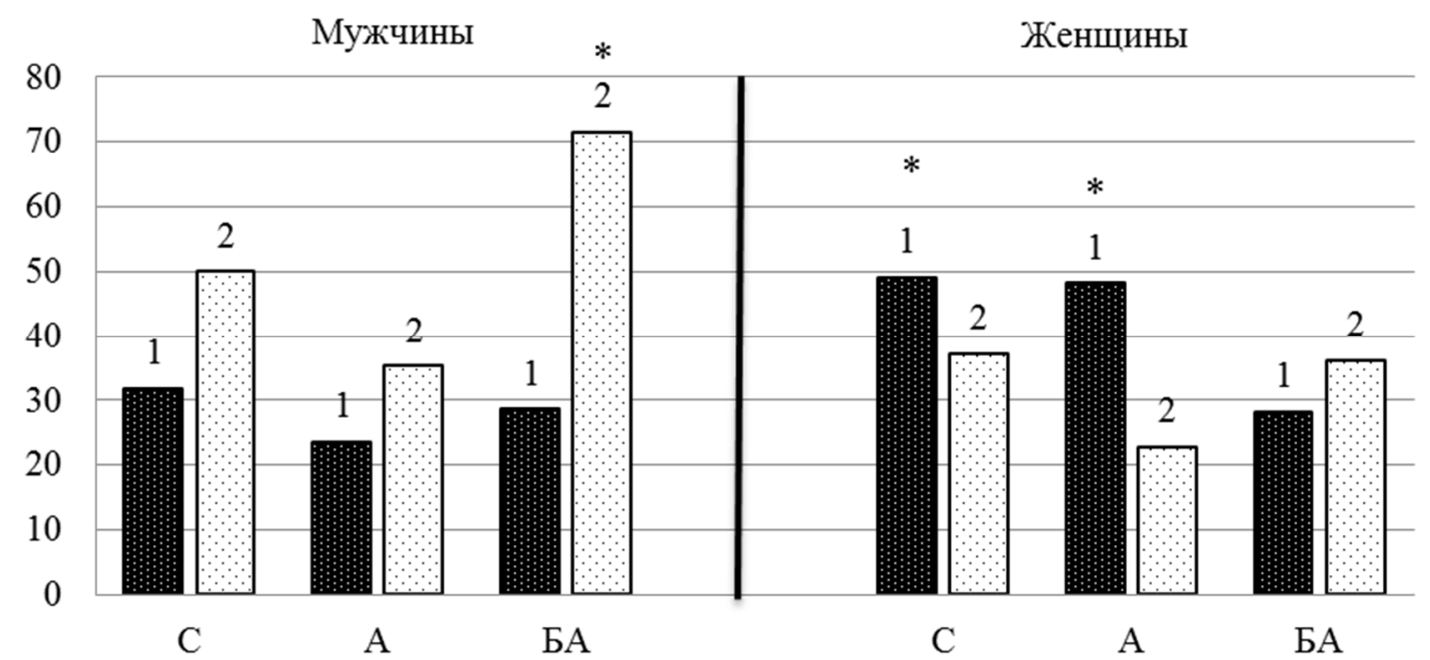

Рис. 1. Соотношение в процентах ответов исследуемых о переживании ощущений холода или боли в период холодового воздействия.

Условные обозначения: $\mathrm{C}$ - акцентуация стенических свойств темперамента: А - акцентуация стенических свойств: БА - без акцентуаций; 1 - переживание боли; 2 - ответы о переживаниях, связанных с холодом; * - статистически достоверные (при р $<0,05)$ различия показателей между группами испытуемых с акцентуацией и без акцентуации свойств темперамента.

Что касается сенсорного восприятия и эмоционального переживания боли, то их показатели оказались выше - в пределах от 3,7 до 20,8\% - у лиц с акцентуированными свойствами темперамента по сравнению с их величинами при отсутствии акцентуаций, но уровня статистической достоверности достигает только балльная оценка сенсорного восприятия боли у женщин с акцентуацией стенических свойств.

В дополнение к указанным индексам переживания боли следует отметить, что переносимость боли была понижена у 10-15\% исследуемых с акцентуацией свойств темперамента, поскольку 
они вынимали руку на 10-40 сек. от начала действия холода.

В свободном описании исследуемыми их переживаний в период холодового раздражения определенным образом соотносятся характеристики ощущений холода и боли, их объем и динамика. Ощущение холода находило отражение в сравнениях с игрой в снежки, стиркой в холодной воде, охлаждением зимой рук без перчаток, купанием в холодной реке и др. Боль переживали как онемение, сдавление, сжатие, ассоциируемые со страхом, опасением, что она станет невыносимой.

Соотношение этих реакций представлено на рис. 1. Как видно из рисунка, у мужчин всех сравниваемых групп в описаниях преобладали характеристики ощущений холода - в наибольшей степени у мужчин с акцентуацией стенических свойств (до 50\%) и без акцентуаций (71,5\%). У женщин же с акцентуированными темпераментальными свойствами в описаниях чаще - до $49,0 \%$ и 48,2\% - внимание фиксировалось на ощущении боли.

Для всех исследуемых - мужчин и женщин при акцентуациях свойств темперамента частота сосредоточенности на ощущении боли достоверно выше $(\mathrm{p}<0,05)$, чем у женщин без акцентуации свойств, а частота описаний холода у лиц с усилением стенических полюсов факторов темперамента выше $(\mathrm{p}<0,05)$, чем при усилении астенических.

Эти данные согласуются с оценками когнитивных реакций по результатам анкетирования, представленным на рис. 2. Среди ответов, характеризующих психофизиологическую адаптацию исследуемых к холодовому воздействию (оценка боли, стремление к избеганию негативного ощущения и придание ситуации черт «катастрофич- ности»), у более чем половины участников с акцентуированными свойствами темперамента преобладают катастрофичные суждения. При акцентуации астенических свойств их частота возрастает до 50,9-54,6\% ответов, в то время как при отсутствии акцентуации они встречаются у $25-27 \%$ участников.

При определении коррелятивной связи между компонентами, характеризующими холодовую боль, статистически достоверные величины коэффициентов корреляции (при $\mathrm{p}<0,001)$ установлены в первую очередь между показателями сенсорного восприятия и эмоционального переживания боли у женщин и мужчин с акцентуацией астенических свойств темперамента и у женщин, не имеющих акцентуаций (таблица 2). Статистически достоверно высокая коррелятивная связь установлена также между показателями интенсивности боли и ее сенсорным восприятием, а также болевой чувствительностью и сенсорным восприятием у мужчин с акцентуированными темпераментальными свойствами.

При анализе цветового выбора, ассоциированного с холодовой болью (таблица 3), обращает на себя внимание прежде всего предпочтение (до 33,3\%) выбора синего цвета всеми исследуемыми, не имеющими акцентуаций свойств темперамента, причем оно было статистически достоверно выше (при $р<0,001)$, чем при акцентуации стенических свойств. У мужчин с акцентуированными темпераментальными свойствами в целом отмечается более частый выбор красного (20,0\%) и фиолетового (до 18,7\%) цветов. Отмечено также предпочтение красного цвета у женщин всех групп (особенно при акцентуации астенических свойств). В отличие от мужчин женщины всех групп чаще выбирали (до 11-14\%) черный цвет.



Рис. 2. Выраженность в процентах от числа исследований когнитивных реакций на холодовую боль.

Условные обозначения: 1 - переживание повышенной интенсивности боли; 2 - желание избегания болевых ощущений; 3 - страх усиления боли и ее негативных последствий (катастрофирование); * - статистически достоверные различия при р $<0,05$; ** - при $\mathrm{p}<0,01 ; * * *$ - при $\mathrm{p}<0,001$. 
Величины коэффициентов корреляции между показателями холодовой боли

\begin{tabular}{|c|c|c|c|c|c|c|c|}
\hline \multirow{2}{*}{$\begin{array}{l}\begin{array}{l}\text { Группы } \\
\text { исследуемых }\end{array} \\
\end{array}$} & \multirow[b]{2}{*}{$\mathrm{n}$} & \multicolumn{6}{|c|}{ Величины коэффициентов корреляции } \\
\hline & & ПБ-ИБ & ПБ-СВ & ПБ-ЭП & ИБ-СВ & ИБ-ЭП & СВ-ЭП \\
\hline \multicolumn{8}{|c|}{ мужчины } \\
\hline Акцентуация стенических свойств & 19 & $-0,368$ & $-0,131$ & $-0,323$ & $-0,290$ & 0,121 & $-0,270$ \\
\hline Акцентуация астенических свойств & 18 & 0,123 & $0,400^{*}$ & 0,582 & $-0,780^{* * * *}$ & $-0,375$ & $0,615^{* *}$ \\
\hline Без акцентуации свойств & 7 & $0,570^{*}$ & 0,227 & 0,278 & $-0,225$ & 0,059 & \\
\hline \multicolumn{8}{|c|}{ женщины } \\
\hline Акцентуация стенических свойств & 46 & 0,072 & $-0,004$ & 0,009 & $-0,191$ & $-0,001$ & 0,029 \\
\hline Акцентуация астенических свойств & 80 & $-0,149$ & $-0,225$ & $-0,124$ & 0,048 & 0,121 & $0,572^{* *}$ \\
\hline Без акцентуации свойств & 8 & $-0,450$ & $-0,463$ & $-0,409$ & $-0,180$ & $-0,122$ & $0,965^{* * *}$ \\
\hline
\end{tabular}

Примечание: ПБ - порог боли; ИБ - интенсивность боли; СВ - сенсорное восприятие к боли; ЭП - эмоциональное переживание; $\mathrm{n}$ - число исследуемых; обозначение достоверности величин коэффициентов корреляции: * - при $\mathrm{p}<0,05$; $* *-\mathrm{p}<0,01 ; * * *-\mathrm{p}<0,01$.

Таблица 3

Частота (в процентах) предпочтения цветов при переживании холодовой боли у исследуемых с различными свойствами темперамента

\begin{tabular}{|c|c|c|c|c|c|c|c|c|c|c|c|c|}
\hline Показатели свойств темперамента & \multicolumn{6}{|c|}{ Мужчины } & \multicolumn{6}{|c|}{ Женщины } \\
\hline Цветовой выбор & $\mathrm{n}$ & $\mathrm{C}$ & $\mathrm{n}$ & A & $\mathrm{n}$ & БА & $\mathrm{n}$ & $\mathrm{C}$ & $\mathrm{n}$ & A & $\mathrm{n}$ & БА \\
\hline Синий, зеленый & 14 & 28,0 & 19 & 39,6 & 8 & 44,4 & 40 & 31,2 & 37 & $29,5^{*}$ & 12 & $\overline{54,5}$ \\
\hline Красный, желтый, фиолетовый & 28 & 56,0 & 23 & 50,0 & 7 & 38,9 & 52 & 40,6 & 9 & $50,8^{*}$ & 6 & 24,0 \\
\hline Коричневый, черный & 8 & 16,0 & 5 & 10,4 & 3 & 16,6 & 36 & 28,1 & 38 & 19,7 & 4 & 16,7 \\
\hline
\end{tabular}

Примечание: С - акцентуация стенических свойств, А - астенических, БА - без акцентуации; n - число измерений; * - статистически достоверные различия при сопоставлениях у женщин: «синий, зеленый» - А-БА; «красный, желтый, фиолетовый» - А-БА.

В нашей работе применена модель боли у человека, вызванной погружением кисти руки в холодную воду. В настоящее время выяснены ноцицепторы и семейство сенсорных трансдукторов в них, принадлежащих к Transient Receptor Potential Family, в частности TRPA $121,29,31]$, обеспечивающих возникновение холодовой боли.

Считают, что воспроизводимая в этой модели боль аналогична миофасциальной и имеет тонический характер, что позволяет выполнить необходимые измерения: порога, интенсивности, выносливости, сенсорного восприятия и эмоционального переживания, а также когнитивные ответы.

Эта стандартно воспроизводимая модель боли исследована нами у людей с различными типами темперамента для выявления индивидуальных особенностей.

Как известно, темперамент генетически детерминирован и представляет биологически обоснованный формально-динамический аспект психических процессов: активность (интенсивность, скорость, темп) во взаимодействии с внешним миром и эмоциональность (стиль эмоционального реагирования).
Применен метод, позволяющий измерять по 10-балльной шкале свойства темперамента и выразить их обобщенно в 3 факторах второго порядка: ЭС-ЭН; СА-СП; ПА-ПП. По результатам измерений выделены исследуемые с усилением (акцентуацией) противоположных полюсов 3-факторной модели темперамента, а именно, - с усилением стенических и астенических свойств.

Оказалось, что тип темперамента определенным образом влияет на показатели холодовой боли в примененной модели. Так, у исследуемых с акцентуацией его свойств в сравнении с участниками, не имеющими акцентуаций, были выше показатели интенсивности боли, сенсорного ее восприятия, эмоционального переживания и катастрофичности. Что же касается уровня болевой чувствительности, то у женщин с акцентуацией свойств темперамента он оказался ниже, а у мужчин выше, чем при отсутствии акцентуаций.

Большее напряжение в переживании холодовой боли у лиц с акцентуированными свойствами темперамента подтверждается предпочтением у них красного, фиолетового и черного цветов, которые считаются ассоциированными с негативными эмоциями человека [1]. Следует отметить и 
тенденцию к большей выраженности ряда показателей, в частности катастрофичности, при акцентуации астенических свойств.

Установлены также гендерные различия показателей холодовой боли, наиболее выраженные при сравнении групп мужчин и женщин, не имеющих акцентуаций темпераментальных свойств. Так, у женщин этой группы уровень болевой чувствительности и интенсивность боли статистически достоверно (при р $<0,05)$ выше, чем у аналогичной группы мужчин.

Подобное соотношение между показателями боли сохраняется у мужчин и женщин с акцентуированными свойствами темперамента, а именно: у женщин выше, чем у мужчин, показатели сенсорного восприятия холодовой боли и ее эмоционального переживания (особенно при акцентуации астенических свойств). Отмечается также преобладание переживаний боли, а не холода, и большая частота ассоциаций с черным цветом. Мужчины с акцентуацией астенических свойств темперамента характеризуются статистически высокодостоверной коррелятивной связью между показателями болевой чувствительности, с одной стороны, и интенсивности боли, ее сенсорного восприятия и эмоционального переживания - с другой.

Естественно думать, что влияние свойств темперамента на возникновение боли и ее показатели осуществляется через оба его аспекта - активность и эмоциональность - и проявляется в индивидуальных особенностях соматосенсорных и когнитивно-поведенческих характеристик.

При исследовании экспериментальной и клинической боли выделены психофизиологические процессы, связанные с болью: тревожность, страх, катастрофирование, самообладание и адаптивная интерпретация. На моделях холодовой и тепловой боли установлено, что уровень тревожности коррелировал с болевой чувствительностью: меньшая болевая чувствительность связана с низкими шкалами тревожности [13]. У мужчин усиленная тревожность сочеталась с большей интенсивностью боли. Что касается страха, то он в значительной степени предопределял интенсивность холодовой боли, но усиленные тревожность и страх оказывали тормозное влияние на ее переживание [27]. Отмечена ассоциация между страхом боли и катастрофированием. При этом когнитивные факторы дифференцированно связаны с уровнями боли и обеспечивали дополнительные (до 30\%) изменения ее интенсивности. Установлено также, что катастрофирование и тревога уменьшали ослабляющее холодовую боль влияние выполнения задачи отвлечения внимания и внешнего действия $[17,20]$.
Что касается активности как аспекта темперамента, то он может отражаться в психофизиологических болевых ответах, которые, как установлено, параллельны величине активации мозга в пределах нейроматрикса [13]. Представляет особый интерес тот факт, что акцентуированные типы темперамента характеризуются усиленной генерализованной активацией ЦНС и повышенной вегетосоматической реактивностью [10]. Естественно полагать, что одним из механизмов этой зависимости может быть более выраженный и продолжительный ангиоспазм при холодовой прессорной пробе у здоровых добровольцев с высокой адренергической активацией [7].

С особенностями выделенных типов темперамента согласуются и полученные нами данные о более высоких показателях восприятия и переживания холодовой боли у лиц с акцентуированными типами. Эта тенденция проявляется и у мужчин, и у женщин, хотя выявлены определенные половые различия.

В имеющихся в литературе многочисленных исследованиях экспериментальной и клинической боли показано, что в происхождении гендерных различий могут играть роль различные биопсихосоциальные факторы $[14,18]$. При этом у женщин отмечали более высокую болевую чувствительность и низкую толерантность, в том числе при холодовой боли. Что же касается механизмов, лежащих в основе половых различий, то они включали психологический уровень, в частности, влияние стереотипных гендерных ролей, и нейробиологические факторы, особенно модулирующие эффекты половых гормонов [14, 24, 26, 30]. Так, установлено, что при боли, вызванной в эксперименте действием формалина, эстрадиол влиял на ответ первичных афферентных волокон, а также на центральную сенситизацию и болевое поведение [25]. Показано также, что половые гормоны могут модулировать боль через многие системы ЦНС, в частности, эндогенную опиоидную систему, дофаминеричесие и серотонинергические пути, вовлеченные в ноцицептивный процесс [11].

Таким образом, наша концепция состоит в том, что темперамент как интегративный параметр индивидуальности является предиктором особенностей возникновения боли, ее сенсорного восприятия и эмоционального переживания, включая тревогу, страх и катастрофирование. Именно темперамент характеризует для индивидуума его активность на интеллектуальном, психомоторном и социальном уровнях и его эмоциональность, включая эмоциональную возбудимость, модальность и интенсивность эмоций. С применением экспериментальной модели холодой боли нами установлено, что типы темпера- 
мента с усилением (акцентуацией) полюсов полярных факторов эмоциональности, социальной и предметной активности являются предикторами более высокого уровня болевой чувствительности, сенсорных и эмоциональных компонентов болевых ответов.

Полученные данные позволяют заключить, что определение типа темперамента позволяет прогнозировать индивидуальные особенности болевой чувствительности и выраженности сенсорного и эмоционального переживания боли у человека в эксперименте и клинике. Это может быть использовано для индивидуализации лечения и профилактики болевых синдромов.

\section{ЛИТЕРАТУРА}

1. Адашинская Г.А., Ениколопов С.Н., Мейзеров Е.Е. Боль и цвет // Психолог. журн. - 2005. - Т. 26, № 3. - С. 74-80.

2. Адашинская Г.А., Мейзеров Е.Е. Многомерный вербально-цветовой тест (способ оценки боли): пособие для врачей. - М. : Федерал. науч. Клин.эксперимент. центр традиционных методов диагностики и лечения МЗ РФ, 2004. - 47 с.

3. Воронова И.П., Тужикова А.А., Козырева Т.В. Экспрессия генов термочувствительных TRPканалов в гипоталамусе крыс в норме и при адактации к холоду // Российский физиол. журн. им. И.М. Сеченова. - 2012. - Т. 98, № 9. - С. 11011110 .

4. Козырева Т.В., Ткаченко Е.Я., Потапова Т.А., Ромащенко А.Г., Воевода М.И. Связь однонуклеотидного полиморфизма rs11562975 гена термочувствительного ионного канала TRPM 8 с чувствительностью человека к холоду и ментолу // Физиология человека. - 2011. - Т. 37, № 2. - С. 71-76.

5. Кукушкин М.Л., Игонькина С.И. Значение ГАМК в патогенезе болевых синдромов // Патол. физиология и эксперим. терапия. - 2014. - № 1. - С. 68-78.

6. Маслюков П.М., Просева В.В., Корзина М.Б., Ноздрачев А.Д. Нейрохимические особенности сенсорных нейронов в онтогенезе // Российский физиол. ж. им. И.М. Сеченова. - 2013. - Т. 99, № 7. - С. 777-792.

7. Новикова И.Н., Дунаев А.В., Сидорова В.В., Крупаткин А.И. Функциональное состояние микроциркуляторно-тканевых систем при холодовой прессорной пробе // Физиология человека. - 2015. - T. 41, № 6. - C. 95-103.

8. Пантелеев С.С., Бусыгина И.И., Любашина О.А. Эффекты селективной блокады $5 \mathrm{HT}_{3}$-рецепторов на физиологические маркеры абдоминальной боли у бодрствующих собак // Российский физиол. журн. им. И.М. Сеченова. - 2013. - Т. 99, № 4. C. 471-483.

9. Плотников В.В., Северьянова Л.А., Плотников Д.В., Бердников Д.В. Тест акцентуации свойств темперамента (ТАСТ): метод. рук. - СПб. : Иматон, 2006. - 80 с.
10. Плотников В.В., Северьянова Л.А., Плотников Д.В. Психосоматическая медицина: проблемы, возможные направления исследования, методы // Профилактическая и клиническая медицина. - 2011. T. 2 (39), № 2. - C. 271-274.

11. Ростовиева Е.В., Бондарева Э.А., Агапов И.И. Молекулярно-генетические аспекты индивидуальных различий в болеощущении и терморегуляции // Физиология человека. - 2009. - Т. 35, № 1. - С. 130-140.

12. Русалов B.M. Темперамент в структуре индивидуальности человека: Дифференциальнопсихологические и психологические исследования. - М. : Изд-во «Институт психологии РАН», 2012. $-528 \mathrm{c}$.

13. Edwards R.R., Fillingim R.B. Self - reported pain sensitivity: lack of correlation with pain threshold and tolerance // Eur J Pain. - 2007. - Vol. 11, N 5. P. 594-598.

14. Fillingim R.B., King C.D., Ribeiro-Dasilva M.C., Rahim-Williams B., Riley Y.L. 3rd. Sex, Gender, and pain: a review of recent clinical and experimental findings // J Pain. - 2009. - Vol. 10, N 5. - P. 447485. - doi: 10.1016/j.jpain.2008.12.001.

15. Fillingim R.B., Wallace M.R., Hebstman D.M., Ribeiro-Dasilva M., Staud R. Genetic contribution to pain: a review of findings in humans // Oral Diseases. - 2008. - Vol. 14, N 8. - P. 673-682. - doi: 10.1111/j.1601-0825.2008.01458.x.

16. Hartrick C.T., Rozek R.Y. Tapentadol in pain management: a $\mu$-opioid receptor agonist and noradrenaline reuptake inhibiter // CNS Drugs. 2011. - Vol. 25, N 5. - P. 359-370. - doi: 10.2165/11589080-000000000-00000.

17. Karsdorp P.A., Geenen R., Vlaeyen Y.W. Response inhibition predicts painful task duration and performance in healthy individuals performing a cold pressor task in a motivational context // Europ. J. Pain. - 2014. - Vol.18, N 1. - P. 92-100. - doi: 10.1002/j.1532-2149.2013.00348.x.

18. Kindler L., Valencia C., Fillingim R.B., George S. Sex differences in experimental and clinical pain sensitivity for patients with shoulder pain // Eur J Pain. - 2011. - Vol. 15, N 2. - P. 118-123. - doi: 10.1016/j.ejpain.2010.06.001.

19. Knowlton W.M., Palkar R., Lippololt E.K., McCoy D.D., Baluch F., Chen Y., McKemy D.D. A sensory - labeled line for cold: TRPM 8 - expressing sensory neurons the cellular basis for cold, cold pain, and cooling - mediated analgesic // J. Neurosci. 2013. - Vol. 33, N 7. - P. 2837-2848. - doi: 10.1523/JNEUROSCI.1943-12.2013.

20. Loreto-Quijada D., Gutierrez-Maldonado J., Gutierrez-Martinez O., Nieto $R$. Testing a virtual reality intervention for pain control // Eur J Pain. 2013. - Vol. 17, N 9. - P. 1403-1410. - doi: 10.1002/j.1532-2149.2013.00316.x.

21. Lu S., Baad-Ylansen L., Zhang Z., Svensson P. Somatosensory profiling of intra - oral capsaicin and menthol in healthy subjects // Eur J. Oral Sci. 2013. - Vol. 121, N 1. - P. 29-35. - doi: 10.1111/eos. 12014 . 
22. Mazzola L., Isnard J., Peyron R., Mauguiere F. Stimulation of the human cortex and the experience of pain: wilder Penfield's observations revisited. // Brain. - 2012. - Vol. 135, Pt. 2. - P. 631-640. - doi: 10.1093/brain/awr265.

23. Meulders A., Vansteenwegen D., Vlaeven Y.W. Women, but not men, report increasingly more pain, during repeated (un) predictable painful electrocutaneous stimulation: Evidence for mediation by fear of pain // Pain. - 2012. - Vol. 153, N 5. P. 1030-1041. - doi: 10.1016/j.pain.2012.02.005.

24. Morgan C., Conway P., Currie C.Y. The relationship between self - reported severe pain and measures of socio - economic disadvantage // Eur J. Pain. 2011. - Vol. 15, N 10. - P. 1107-1111. - doi: 10.1016/j.ejpain.2011.04.010.

25. Nazarian A., Tenajuca Y.M., Almasarweh F., Armendariz A., Are D. Sex differences in formalin evoked primary afferent release of substance P // Eur J Pain. - 2014. - Vol. 18, N 1. - P. 39-46. - doi: 10.1002/j.1532-2149.2013.00346.x.

26. Racine M., Tousignant-Laflamme Y., Kloda L., Dion D., Dupuis G., Choiniere M. A systemic literature review of 10 years of research on sex / gender and pain reception - Part 2: Do biopsychosoci factors alter pain sensitivity differently in women and men // Pain. - 2012. - Vol. 153, N 3. - P. 619-635. doi: 10.1016/j.pain.2011.11.026.
27. Rhudy Y.L., Meagher M.W. Fear and anxiety: divergent effects on human pain thresholds // Pain. 2000. - Vol. 84, N 1. - P. 65-75.

28. Rothbart M.R. Temperament, development and personality // Current Directions in Psychological Science. - 2007. - Vol. 16, N 4. - P. 207-212. - doi: 10.1111/j.1467-8721.2007.00505.x

29. Rowbotham M.C., Nothaft W., Duan W.R., Wang Y., Faltynek C., McGaraughty S., Chu K.L., Svensson P. Oral and cutaneous thermosensory profile of selective TRPV1 inhibition by ABT-102 in a randomized healthy volunteer trial // Pain. - 2011. - Vol. 152, $\mathrm{N}$ 5. $-\quad$ P. 1192-1200. $\quad$. doi: 10.1016/j.pain.2011.01.051.

30. Stubbs D., Krebs E., Bair M., Damush T., Wu J., Kroenke K. Sex Differences in Pain - Related Disability among Primary Care Patients with Chronic Musculoskeletal Pain // Pain Med J. - 2010. - Vol. 11, $\mathrm{N} 2$. - P. 232-239. - doi: 10.1111/j.15264637.2009.00760.x.

31. Vetter I., Hein A., Sattler S., Hessler S., Touska F., Bressan E., Parra A., Hager U., Leffler A., Boukalova S., Nissen M., Lewis R.J., Belmonte K., Alzheimer K., Huth T., Vlachova V., Reeh P., Zimmermann $K$. Amplified cold transduction in native nociceptors by M-channels Inhibition // J. Neurosci. 2013. - Vol. 33, N 42. - P. 16627-16641. - doi: 10.1523/JNEUROSCI.1473-13.2013. 